\title{
Interdisciplinaridade no ensino superior: desafios e diálogos na
}

\section{educação}

La interdisciplinariedad en la educación superior: retos y diálogos en la educación

Interdisciplinarity in higher education: challenges and dialogues in

\author{
education
}

\author{
Arthur Saldanha dos Santos ${ }^{1}$ \\ Greiciele Soares da Silva ${ }^{2}$
}

\begin{abstract}
Resumo
O objetivo do presente artigo, tendo em vista que a interdisciplinaridade surge como uma perspectiva de leitura e compreensão de uma realidade cada vez mais complexa e multifacetada consiste em esboçar um breve levantamento teórico de abordagens tradicionais no ensino superior em contraposição aos processos de formação interdisciplinar dos acadêmicos. Tais percepções evidenciam que a interdisciplinaridade não é um modismo pósmoderno, mas sim uma necessidade de integração de conhecimentos à formação não só acadêmica, mas sim humana e social. Dessa forma, este estudo utiliza a revisão teórica interdisciplinar, sendo dividido em algumas discussões: processos históricos e a tradicionalidade das Universidades; as novas conjunturas de formação acadêmica interdisciplinar; desafios e competências no processo formativo interdisciplinar no ensino superior e a formação docente. A interdisciplinaridade é vista dessa forma, como abordagem metodológica que integra as disciplinas e seus conhecimentos, a fim de produzir uma ciência mais participativa e completa, dotada de distintos posicionamentos, experiências e conhecimentos para o processo educacional.
\end{abstract}

Palavras-Chave: Ensino Superior; Interdisciplinaridade; Tradicionalidade.

\section{Resumen}

El propósito de este artículo, teniendo en cuenta que la interdisciplinariedad surge como una perspectiva de la lectura y la comprensión de una realidad cada vez más compleja y multifacética es esbozar un breve estudio teórico de los enfoques tradicionales de la educación superior en comparación con los procesos de formación interdisciplinarios académicos. Tales percepciones muestran que la interdisciplinariedad no es una moda postmoderna, sino una necesidad de integrar la formación del conocimiento no sólo académica, sino humano y social. Por lo tanto, este estudio utiliza revisión teórica interdisciplinaria, dividido en algunas discusiones: los procesos históricos y el tradicionalismo de las universidades; las nuevas situaciones de formación académica interdisciplinaria; retos y habilidades en el proceso educativo interdisciplinar en la educación superior y la formación de maestros. El enfoque interdisciplinar se ve de esta manera, como un enfoque metodológico que integre las disciplinas y conocimientos con el fin de producir una ciencia más participativa y completa, dotada de diferentes posiciones, experiencia y conocimiento para el proceso educativo.

Palabras claves: Enseñanza Superior; Interdisciplinariedad; Tradicionalismo.

\footnotetext{
${ }^{1}$ Mestrando em "Sociedade, Ambiente e Território" pela Associação entre a Universidade Federal de Minas Gerais - UFMG e a Universidade Estadual de Montes Claros - Unimontes. Bolsista pela Coordenação de Aperfeiçoamento de Pessoal de Nível Superior - CAPES. E-mal: arthur-ufvjm@ hotmail.com.

2 Mestranda no Programa de Pós Graduação em Sociedade, Ambiente e Território - PPGSAT associado Universidade Federal de Minas Gerais - UFMG e Universidade Estadual de Montes Claros - UNIMONTES. Email: greicytstsoares123@yahoo.com.br.
} 


\begin{abstract}
The aim of this article, considering that interdisciplinarity emerges as a perspective of reading and understanding of an increasingly complex and multifaceted reality, consists in sketching a brief theoretical survey of traditional approaches in higher education as opposed to the interdisciplinary formation processes of Academics. Such perceptions show that interdisciplinarity is not a postmodern idiom, but a necessity of integrating knowledge into the formation not only of academic, but of human and social formation. In this way, this study uses the interdisciplinary theoretical revision, being divided in some discussions: historical processes and the traditionality of the Universities; The new conjunctures of interdisciplinary academic formation; Challenges and competences in the interdisciplinary training process in higher education and teacher training. Interdisciplinarity is seen in this way, as a methodological approach that integrates the disciplines and their knowledge, in order to produce a more participative and complete science, endowed with different positions, experiences and knowledge for the educational process.
\end{abstract}

Keywords: Higher Education; Interdisciplinarity; Traditionality.

\title{
1. Introdução
}

O presente trabalho busca discutir, por meio de revisão bibliográfica, a importância da interdisciplinaridade para o aprofundamento dos diferentes tipos de conhecimentos. Com o passar dos anos, várias foram as transformações no campo da ciência, que possibilitaram uma "quase" superação da dicotomia entre sociedade/natureza e homem/animal. Quando ressaltamos a quase superação, buscamos enfatizar, que ainda hoje, no campo científico existe, o que Santos (2005) caracteriza como "guerra da ciência", onde ocorre não apenas a separação entre as formas de conhecimento, mas também a sua especialização, fragmentação e hierarquização. A ideia de arrogância científica ainda se encontra presente no campo das ideias, o que é incorporado e reproduzido dentro dos cursos superiores nas universidades públicas e privadas, como veremos adiante.

Dessa forma, embora a sociedade já tenha iniciado um processo de modificação da percepção e da sensibilidade do homem sobre os demais elementos da natureza, e alguns campos de conhecimento incorporado à ideia de que o conhecimento não é unicamente científico, nem exclusivo de determinados campos de estudos, o que é hegemônico é a prática da separação entre conhecimentos e áreas, sendo a universidade o local do único conhecimento (reconhecido como o único passível de ser considerado o certo e verdadeiro) existente e possível: o conhecimento científico racional e especializado.

Segundo Santos $(2005$, p. 15) "é necessário voltar às coisas simples, à capacidade de formular perguntas simples, que, como Einstein costuma dizer, só uma criança pode fazer, mas que, depois de feitas, são capazes de trazer uma luz nova à nossa perplexidade". Nesse sentido, antes de compreender o papel da interdisciplinaridade no ensino superior, cabe levantar algumas discussões didáticas sobre a formação de educadores (ISAÍA, 2006). Assim, 
esses desafios e perspectivas na formação e didática dos docentes, entendidos aqui como o cerne fundamental no processo do diálogo e da construção do saber em conjunto com os alunos, serão discutidos.

Portanto, nesse artigo, refletiremos sobre a tradicionalidade no ensino superior e suas vertentes: aluno-professor e campo científico; o processo de interdisciplinaridade na educação atual, onde se busca a aproximação entre as disciplinas/seus conhecimentos e, os desafios enfrentados por essa metodologia que visa integrar os saberes e suas formas diferenciadas de percepção científica (POMBO, 2005).

\section{A tradicionalidade no ensino superior}

A "tradicionalidade" apresentada pelo presente trabalho refere-se a dois aspectos, primeiro, relação aluno-professor, e segundo, campo científico, que discutida de forma associada, representa, na perspectiva deste estudo, um quadro complexo para o ensino superior.

No primeiro, o aspecto de "tradicional" se relaciona aos modelos educacionais que são inspirados no processo de "educação bancária" criticada por Freire (1974), pois compreende que a aprendizagem ocorre por meio de "depósitos", em que o professor deposita todo o "seu conhecimento" no aluno, que por sua vez, se faz presente unicamente como receptor de informação. No segundo caso, o aspecto "tradicional" traz o elemento da hierarquização dos saberes e das ciências dentro do campo científico, onde as ciências naturais, entendidas como objetivas, são colocadas em patamares superiores em relação às ciências humanas e aos demais saberes tidos como tradicionais, sendo estes representados por subjetividades, desconsiderando a ideia de Santos $(2005$, p. 9) de que "todo conhecimento científico é socialmente construído".

O caráter "tradicional" se constitui como desafio para o processo de aprendizagem, uma vez que é possível levantar alguns questionamentos acerca da relação existente entre alunos e professores e do local que a ciência deve ocupar na sociedade. É dentro dessa compreensão de tradicional, que o presente trabalho busca discutir as dificuldades do curso superior, sendo a objetividade um elemento fundamental para se refletir a constituição e produção da ciência nas universidades, onde os modelos de avaliação de todo o processo educacional ocorrem por meio de avaliações de conteúdos, entendidas como únicas formas efetivas de se "medir" o conhecimento de cada aluno.

Os denominados "sistemas nacionais de ensino" segundo Saviani (2001, p. 5), foi inspirado na ideia de que a "educação é direito de todos e dever do estado", sendo essa nova 
sociedade resultado e forma de consolidar o poder da burguesia, nova classe política e econômica, que surgia no século XIX. Essa nova mentalidade tinha como desejo a transformação dos súditos em cidadãos, transformação esta que ocorreria por meio do ensino. Nesta perspectiva segundo Saviani (2001, p. 6) a marginalização ocorria pela forma de separação entre "ignorantes" e "esclarecidos", sendo então a escola o "antídoto à ignorância".

As escolas eram organizadas em forma de classes, cada uma contando com um professor que expunha as lições, que os alunos seguiam atentamente, e aplicava os exercícios, que os alunos deveriam realizar disciplinadamente. (SAVIANI, 2001, p. 6)

Nesse formato, a escola não apenas não realizou seus objetivos como teve de reconhecer a existência de deficiências. É nesse cenário, que foram realizadas várias críticas à pedagogia tradicional, sendo nas primeiras décadas do XX momento de construção de uma "pedagogia nova". Segundo Saviani (2001, p. 7) nesse movimento de reforma, conhecido como "escolanovismo", o marginalizado não era o "ignorante", mas o "rejeitado", sendo a escola o meio para corrigir o fenômeno da marginalidade.

Na perspectiva da "pedagogia nova", segundo Saviani (2001, p. 8), para equalização social, a educação é entendida como "um instrumento de correção da marginalidade na medida em que cumprir a função de ajustar ou adaptar os indivíduos à sociedade". Entretanto, para o autor (p. 10) esse modelo não mudou de forma significativa o formato organizacional das escolas.

Dessa forma, "Escola Nova" se organiza de forma experimental, atendendo a pequenos grupos pertencente a elite, aprimorando essa forma de ensino elitista, o que ao invés de solucionar, agravou ainda mais a situação da escola. No início da década de 1960, no Brasil, emergem as ideias de Paulo Freire e em meados dessa mesma década a Escola Nova se apresenta com menos força, dando espaço para a pedagogia tecnicista (organização, racionalização, mecanização e operacionalização) que segundo Saviani (2001, p. 15) agravou o sistema educacional. De acordo com Freire (1996, p. 83) "faz parte do poder ideológico dominante a inculcação nos dominados da responsabilidade por sua situação", dessa forma a educação não é neutra, cumpre um papel social que é ideológico e político.

Essas teorias podem ser entendidas como "não críticas", pois compreendem a marginalidade como um problema social que pode ser solucionado pela educação. Por outro lado, constituem-se as "teorias críticas" que acreditam que se deve entender a "educação pelas condicionantes sociais", mas que também considera que a educação é a "reprodução da 
sociedade em que ela se insere", sendo essas ideias denominadas de "teorias críticoreprodutivistas". (SAVIANI, 2001, p. 16)

Dentre essas, as três correntes de maior repercussão, segundo Saviani (2001) são: teoria do sistema de ensino como violência simbólica; teoria da escola como aparelho ideológico do estado; e teoria da escola dualista. Essas teorias entendem a educação de formas diferentes, como campo de forças e de dominação e legitimação econômica de determinados grupos; como ideologia que se materializa no aparelho do Estado; e a dualidade entre classes (burguesia/proletariado).

Na perspectiva de Saviani (2001, p. 29) “essas teorias não contêm uma proposta pedagógica. Elas empenham-se tão-somente em explicar o mecanismo de funcionamento da escola tal como ela está constituída". No entanto, segundo o autor, "o papel da teoria crítica da educação é dar substância concreta a essa bandeira de luta de modo a evitar que ela seja apropriada e articulada como os interesses dominantes"

Dentro desse contexto, podemos compreender o ensino superior como uma configuração e reconfiguração constante de interesses de grupos sociais, sendo uma forma de reprodução da dinâmica social, que por sua vez também é possibilitada pela educação, sendo importante entender a relação escola-sociedade.

Romper com a tradicionalidade do ensino superior implica em compreender, como afirma Freire (1996, p. 47) que "ensinar não é transferir conhecimento, mas criar possibilidade para a sua produção ou a sua construção". Quando se estabelece esse processo, os acessos às informações e conhecimentos diversos passam a ser contemplados na interdisciplinaridade. Portanto, o ensinar deve ser construtivo no sentido de sempre estar em conexão com os saberes diversos do conhecimento.

\subsection{Novas conjunturas da formação acadêmica: então, o que venha a ser interdisciplinaridade?}

Na perspectiva de Santos (2005) no campo do conhecimento ocorre uma "guerra da ciência", onde as ciências naturais e as ciências sociais são entendidas enquanto campos opostos, provocando uma hierarquização dos saberes. Dentro desse campo existe um paradigma dominante, o modelo da racionalidade, que se inicia no século XVI pelo domínio das ciências naturais. (SANTOS, 2005, p. 20)

Esse modelo de racionalidade, segundo Santos (2005, p. 21), é um modelo totalitário, pois nega o caráter racional aos outros conhecimentos que não se fundamentam em seus princípios e regras metodológicas, sendo consideradas "intrusas: o senso comum e as 
chamadas humanidades ou estudos humanísticos", o que caracteriza uma arrogância científica. No entanto, no século XIX essas regras e princípios metodológicos das ciências naturais se estendem às ciências sociais. Esse processo de divisão e estratificação no campo científico se expressa por duas visões de mundo: conhecimento científico e conhecimento do senso comum. Para Santos (2005, p. 28) no modelo da racionalidade o conhecimento é condicionado ao ato de quantifica, sendo que "o que não é quantificável é cientificamente irrelevante".

É contra essas práticas positivistas nas ciências sociais que, de acordo com Santos (2005, p. 38) a postura antipositivista compreende que "o comportamento humano, ao contrário dos fenômenos naturais, não pode ser descrito e muito menos explicado com base nas suas características exteriores e objetiváveis".

De acordo com Santos (2005, p. 41) essa racionalidade cientifica atravessa uma crise, o que resulta em uma crise do paradigma dominante, uma vez que "o aprofundamento do conhecimento permitiu ver a fragilidade dos pilares do conhecimento". Com a crise de hegemonia dessa ordem cientifica, uma nova ordem científica emerge. O paradigma emergente "é um paradigma de um conhecimento prudente para uma vida decente" e deve ser um paradigma social. (SANTOS, 2005, p. 60)

\footnotetext{
O conhecimento do paradigma emergente tende assim a ser um conhecimento não dualista, um conhecimento que se funda na superação das distinções tão familiares e óbvias que até há pouco considerávamos insubstituíveis, tais como natureza/cultura, natureza/artificial, vivo/inanimado, mente/matéria, observador/observado, subjectivo/objectivo, colectivo/individual, animal/pessoa" (SANTOS, 2005, p. 64)
}

Uma das criticas apresentadas por Santos (2005, p. 74) é que a ciência avança pela especialização "excessiva parcelização e disciplinarização do saber científico faz do cientista um ignorante especializado e que isso acarrete efeitos negativos". No caso do paradigma emergente, o conhecimento busca a totalidade universal, sendo também local.

Um dos pontos importante para esse paradigma emergente é o reconhecimento da limitação de campos de estudos fechados para um conhecimento mais amplo e aprofundado. Dessa forma, percebe-se a necessidade apropriação em outros campos de estudo, entendidos antes como opostos ou "não ciência" para se responder questões que não podem ser respondidas por uma única forma de conhecimento.

A interdisciplinaridade se configura como uma forma de romper com os modelos de conhecimentos que são cada vez mais fragmentados, buscando por meio de uma grande discussão em diferentes campos científicos uma contextualização mais coerente com a 
realidade social. De acordo com Fazenda (1994, p. 24) a discussão da interdisciplinaridade chega ao Brasil na década de 1960, tendo um avanço em sua reflexão a partir de 1970.

Segundo Fazenda (1994, p. 9) "a interdisciplinaridade consolida-se na ousadia da busca, de forma que é sempre pergunta, ou melhor, pesquisa", dessa forma, a autora (p. 11) busca apresentar a "evolução histórico-crítica do conceito de interdisciplinaridade", onde em sua perspectiva "é impossível à construção de uma única, absoluta e geral teoria da interdisciplinaridade" (p. 13), mas ressalta a importância de se pensar "o movimento pelo qual os estudiosos da temática da interdisciplinaridade têm convergido nas três ultimas décadas”. (FAZENDA, 1994, p. 14).

Sobre o movimento da interdisciplinaridade, Fazenda (1994, p. 18) apresenta "em 1970 partimos para uma construção epistemológica da interdisciplinaridade. Em 1980 partimos para a explicitação das contradições epistemológicas decorrentes dessa construção e em 1990 estamos tentando construir uma nova epistemologia, a própria interdisciplinaridade." De forma resumida, a autora apresenta o seguinte perfil para o movimento dessa temática: 1970 - busca pela definição de interdisciplinaridade; 1980 - busca pela explicação de um método para a interdisciplinaridade; e 1990 - a construção de uma teoria da interdisciplinaridade.

O movimento da interdisciplinaridade surge na Europa, principalmente na França e na Itália, em meados da década de 1960 (causa ou consequência, não é o caso de aqui se discutir o lado mais importante da questão, acreditamos que ambos), época em que se insurgem os movimentos estudantis, reivindicando um novo estatuto de universidade e de escola. (FAZENDA, 1994, p. 18)

De acordo com Fazenda (1994, p. 19) esse movimento e posicionamento "nasceu como oposição a todo conhecimento que privilegiava o capitalismo epistemológico de certas ciências", onde a organização curricular evidenciava uma excessiva especialização do conhecimento, sendo esse movimento contra "toda e qualquer proposta de conhecimento que incitava o olhar do aluno numa única, restrita e limitada direção, a uma patologia do saber".

É toda essa discussão, segundo Fazenda (1994, p. 19) "a respeito do papel humanista do conhecimento e da ciência" que iniciou os primeiros debates sobre a interdisciplinaridade. É a partir daí, que "essa tentativa convergiu para a organização de uma nova forma de conceber universidade, na qual as barreiras entre as disciplinas poderiam ser minimizadas, nela seriam estimuladas as atividades de pesquisa coletiva e inovação de ensino". (FAZENDA, 1994, p. 21) 
Um ponto importante para o presente estudo, na perspectiva de Fazenda (1994, p. 22) é que "do ensino universitário deveria se exigir uma atitude interdisciplinar que se caracterizaria pelo respeito ao ensino organizado por disciplinas e por uma revisão das relações existentes entre as disciplinas e entre os problemas da sociedade".

\begin{abstract}
A interdisciplinaridade não seria apenas uma panaceia para assegurar a evolução das universidades, mas, um ponto de vista capaz de exercer uma reflexão aprofundada, crítica e salutar sobre o funcionamento da instituição universitária, permitindo a consolidação da autocrítica, o desenvolvimento da pesquisa e da inovação. (FAZENDA, 1994, p. 22)
\end{abstract}

Dentro dessa perspectiva Fazenda (1994, p. 23) afirma que a "interdisciplinaridade torna-se a grande responsável pelo movimento de redimensionamento teórico das ciências", não sendo uma categoria de conhecimento, mas uma ação, que se desenvolve a partir do desenvolvimento das próprias disciplinas.

\title{
3. Desafios e competências do processo formativo interdisciplinar no ensino superior
}

Sobre a relação interdisciplinaridade e ensino superior, também cabe levantar algumas discussões didáticas sobre a formação de educadores, sendo destacados os desafios e perspectivas na formação dos docentes, entendidos aqui como o cerne fundamental no processo do diálogo e da construção do saber em conjunto com os alunos.

A partir de tais interlocuções e diálogos diversos entre a universidade e seu meio social, podemos questionar o papel do docente (ISAÍA, 2006). Mais que isso, tais conjunturas evidenciam um cenário amplo e interligado de ensino, que evidencia o processo interdisciplinar da educação superior. Para muitos autores, a educação superior das universidades, na pós-modernidade está inserida no discurso não só interdisciplinar, mas também, polidisciplinar ou mesmo transdisciplinar do ensino acadêmico, frente às transformações sociais (NASCIMENTO; PENA-VEGA; SILVEIRA, 2008). Mas, para essa discussão, vamos nos ater apenas à discussão interdisciplinar do processo formativo universitário.

Os desafios do ensino, cada vez mais complexos, no sentido de interpelação entre as áreas do saber, impõem ao docente a necessidade de constante atualização e exige, sobretudo, interesse motivação própria de quem ensina. Entre tais aspectos, a forma de ensinar se torna "o carro chefe" nesse processo, a didática é por assim dizer, grande facilitador do processo de ensino. Nesse sentido, ao levantar as discussões sobre a interdisciplinaridade no ensino 
superior, é preciso compreender as questões de carreira que envolve os docentes das universidades.

Em decorrência desse contexto, instaura-se na educação superior, o exercício solitário da docência centrado no sentimento de desamparo dos professores ante a ausência de interlocução e de conhecimentos pedagógicos compartilhados para o enfrentamento do ato educativo. Como docentes, eles assumem, desde o início da carreira, inteira responsabilidade de cátedra, sem contar com o apoio de professores mais experientes, nem com espaços institucionais voltados para a construção conjunta dos conhecimentos relativos a ser professor. (ISAÍA, 2006, p. 68)

A análise levantada é quanto à formação dos docentes, entendida como "esquecida" pela universidade. Os professores são formados sem preparação didática para a sala de aula e, obrigados a trabalhar com esse meio sem recursos para tal. Esses recursos referem-se ao tempo individual para atualização constante, aprofundamento em pesquisa, eventos, etc. (ISAÍA, 2006). Dessa forma,

\begin{abstract}
Além do sentimento de solidão, os professores desenvolvem outro tipo que pode ser denominado de angústia pedagógica que combina solidão, desamparo e despreparo. Eles, em muitos momentos, estão conscientes da necessidade de transformar suas práticas, mas não sabem qual o caminho percorrer. Assim, sentem necessidade de continuar sua formação e ainda precisam de uma conduta pedagógica mais efetiva, a fim de que possam construir sua docência alicerçada em conhecimento pedagógico compartilhado, que lhes permita encontrar possíveis alternativas de transformação docente. Aliado ao sentimento de solidão, desamparo e despreparo, os professores sentem-se, ainda, pressionados por exigências de seu ambiente de trabalho, principalmente pela cobrança institucional, seja em relação à titulação e à produção, seja em relação à competência pedagógica. (ISAÍA, 2006, p. 68-69)
\end{abstract}

O docente é ainda, muitas das vezes, submetido ao exercício profissional em que é preciso maior adequação entre seu conhecimento de domínio com as necessidades dos alunos de cursos diferentes em que ele leciona.

\footnotetext{
Outro desafio significativo encontra-se na efetiva aplicação da transposição didática à prática educativa dos professores. Sabe-se, contudo, que a estrutura organizacional das IES pode dificultar essa intenção. Assim, quando um mesmo professor desenvolve uma mesma disciplina para diferentes cursos, para os quais não tem formação específica, a questão que se coloca é como fazer a transposição didática do conhecimento científico para o acadêmico e deste para o profissional, quando ele não conhece o campo para o qual pretensamente forma. (ISAÍA, 2006, p. 77)
}

Dessa forma, se os anseios e dificuldades na formação e acompanhamento do docente na universidade fossem de fato, resolvidos, a experiência interdisciplinar em cursos diferentes, poderia ser de valor fundamental para o aprimoramento de seu saber científico e lhe abriria um leque de conhecimentos diversos que até então, envolvia apenas seu domínio 
de base formativa. E ainda, contribuiria para a sua contínua formação pedagógica, tendo em vista que,

\begin{abstract}
Por um processo contínuo, entendemos a necessidade de compreender que o processo de formação dos professores não se encerra na sua preparação inicial, oferecida predominantemente nos cursos de pós-graduação, porém, [...] inicia-se mesmo antes do início de sua carreira, já nos bancos escolares, quando o futuro professor, ainda como aluno, toma contato com seus primeiros exemplos de conduta docente, estendendo-se ao longo de toda sua carreira, num processo de constante aperfeiçoamento. (PACHANE, 2006, p. 133-134)
\end{abstract}

É importante destacar que a interdisciplinaridade, ao ressaltar a importância da conexão entre diferentes áreas de estudos, não deve ser entendida como forma de legitimar o conhecimento tido como científico. O conhecimento entendido como "não científico" também se faz importante para a construção de um conhecimento maior e interdisciplinar. Santos (2004, p. 76) chama a atenção para a importância da "ecologia dos saberes" que consiste na "produção de diálogos entre o saber cientifico ou humanístico, que a universidade produz, e saberes leigos, populares, tradicionais, urbanos, camponeses, provindos de culturas não ocidentais (indígenas, de origem africana, ocidental etc.) que circulam na sociedade”.

Embora existam críticas quanto à interdisciplinaridade, no sentido de fragmentação das ciências, é preciso destacar que o diálogo entre as ciências é o meio fundamental de compreender a sociedade como um todo, em que tais posicionamentos colaboram para formação de campos plurais e pluridimensionais de ensino (VASCONCELOS, 2002). A interdisciplinaridade não deve ser vista como ponto negativo do processo de formação, mas como o abrir-se para o todo, para educação, para a interligação e principalmente, para o outro.

Talvez o facto mais interessante que caracteriza a interdisciplinaridade enquanto fenómeno, não da sociologia, mas, digamos assim, da ontologia da ciência, é que ela só se deixa pensar no cruzamento da perspectiva veritativa e da perspectiva sociológica da ciência. Não se trata agora, nem só da subdivisão contínua dos domínios disciplinares num movimento iniludivelmente orientado em direcção à verdade, nem da expansão quantitativa da comunidade dos investigadores. $\mathrm{O}$ crescimento do conhecimento científico resulta, pelo contrário, de um processo de reordenamento interno das comunidades levado a cabo por um reordenamento das disciplinas. A interdisciplinaridade traduz-se na constante emergência de novas disciplinas que não são mais do que a estabilização institucional e epistemológica de rotinas de cruzamento de disciplinas. Este fenómeno, não apenas torna mais articulado o conjunto dos diversos "ramos" do saber (depois de os ramos principais se terem constituído, as novas ciências, resultantes da sua subdivisão sucessiva, vêm ocupar espaços vazios), como o fazem dilatar, constituindo mesmo novos espaços de investigação, surpreendentes campos de visibilidade. (POMBO, 2006, p. 209). 
A percepção e compreensão sobre a interdisciplinaridade nos processos educacionais devem levar em consideração o papel de integração dessa metodologia, a fim de ampliar os diálogos acadêmicos e contribuir para um conhecimento mais profundo e diversificado, sem centralizações e individualizações de saberes. Por meio da interdisciplinaridade o conhecimento é visto como uma construção social e participativa, em que as distintas disciplinas se unem para pensar e repensar a ciência enquanto valor coletivo.

\section{Considerações finais}

O processo de interdisciplinaridade nos cursos superiores é um desafio a ser encarado e enfrentado no âmbito educacional, como meio de se alcançar a democracia não apenas no ensino, mas na sociedade, reconhecendo a relação entre escola sociedade. A interdisciplinaridade possibilita a construção de pensadores com visões amplas, que se apropriam de vários elementos, de várias áreas, de forma a compreender e atuar social e academicamente em perspectiva macro e contextualizada. O processo de interdisciplinaridade reconhece a importância das diferentes áreas de conhecimento para uma construção intelectual do próprio conhecimento.

É preciso ainda, que para a efetivação da compreensão dinâmica do processo interdisciplinar, considerar a formação docente se apresenta como parte fundamental desse processo. A carreira docente desde sua formação básica deve ser repensada, no sentido de valorizar e refletir sobre o cenário pós-moderno em que as universidades estão inseridas. Dessa forma, estabelecer diálogos entre as ciências não pode ser compreendido como modismo, mas sim, como necessidade e atualização, promoção e interligação de conhecimentos amplos e reflexivos sobre a educação e sua relação com a sociedade.

Portanto, as percepções e compreensões sobre a educação baseada na interdisciplinaridade devem levar em consideração o papel de integração dessa metodologia, a fim de ampliar os diálogos acadêmicos e contribuir para um conhecimento mais profundo e diversificado, sem centralizações e individualizações de saberes. Por meio da interdisciplinaridade o conhecimento é visto como uma construção social e participativa, em que as distintas disciplinas e suas ramificações se unem para pensar e repensar a ciência enquanto valor coletivo construído e voltado para a sociedade. 


\section{Referências}

FAZENDA, Ivani C. Arantes. Interdisciplinaridade: história, teoria e pesquisa. Campinas, SP: Papirus, 1994.

FREIRE, Paulo. Pedagogia da autonomia: saberes necessários à prática educativa. São Paulo: Paz e Terra, 1996.

Pedagogia do oprimido. 1. Ed. Rio de Janeiro: Paz e Terra 1974.

ISAÍA, Silvia Maria de Aguiar. Desafios à docência superior: pressupostos a considerar. In: RISTOFF, D; SEVEGNANI, P. Docência na educação superior. Brasília: INEP. (Coleção Educação Superior em Debate), 2006, p. 65-86.

NASCIMENTO, Elimar Pinheiro do; PENA-VEGA, Alfredo; SILVEIRA, Márcio Antônio da. Organizadores. Interdisciplinaridade e Universidade no Século XXI. Brasília: Editorial Abaré, 2008.

PACHANE, Graziela Giusti. Teoria e prática na formação de professores universitários: elementos para discussão. In: RISTOFF, D; SEVEGNANI, P. Docência na educação superior. Brasília: INEP. (Coleção Educação Superior em Debate), 2006, p. 65-86.

POMBO, Olga. Interdisciplinaridade e integração dos saberes. Liinc em Revista, v.1, n.1, p. 3 -15 , mar. 2005. 208-249.

Práticas interdisciplinares. Sociologias, Porto Alegre, ano 8, nº 15, jan/jun 2006, p.

SAVIANI, Dermeval. Escola e democracia: teorias da educação, curvatura da vara, onze teses sobre a educação política. 34 ed. Revista Campinas/SP, 2001.

SANTOS, Boaventura de Sousa. A universidade do século XXI: para uma reforma democrática e emancipatória da universidade. São Paulo: Cortez, 2004.

. Um discurso sobre a ciência. $3^{\mathrm{a}}$ ed. São Paulo: Cortez, 2005.

VASCONCELOS, Eduardo M. Complexidade e pesquisa interdisciplinar. Epistemologia e metodologia operativa. Petrópolis: Vozes, 2002. 